\title{
Research and Design an Experimental Model for the Determination of Deposits Formation Mechanism in the Combustion Chamber
}

\author{
Van Viet Pham ${ }^{\#}$ \\ ${ }^{\#}$ Vietnam Maritime University, Haiphong city, Vietnam \\ E-mail:phamvanviet@vimaru.edu.vn
}

\begin{abstract}
One of the important researches on fuel use in diesel engines is the basic study of deposits formation in engine combustion chambers. The process of creating deposits in the engine combustion chamber is a complex phenomenon causing many different problems. Therefore, it is necessary to study the mechanism of deposits formation and development in engine combustion chamber when using traditional diesel or biodiesel. The study of combustion chamber deposits in internal engines was conducted to understand the effects of deposits on the engine and how they were formed and developed. Most of the current studies on deposits are carried out using statistical results from vehicle's engines. Testing on real engines requires a long time and long distance travel, which makes the cost of both tests very high, causes damage to the engine during deposits testing. Studying and finding a simpler, more cost-effective experimental model that meets the requirements of the deposits formation testing and assessing the factors that make up them are essential. An experimental model design to determine the formation mechanism of deposits in the combustion chamber is the key point of the paper. This study clarifies the deposits formation of fuel in the engine by using a method called a heated surfaces deposits formation testing (HSDFT) and simulate the accumulation and development of deposits in combustion chamber. This model will help researchers to initially build the database effectively to determine the deposits formation mechanism in the combustion chamber of diesel engines when using different fuel.
\end{abstract}

Keywords — deposits formation; combustion chamber deposits; experimental model; diesel engines.

\section{INTRODUCTION}

Deposits or carbon deposit is a heterogeneous mixture of ash, soot, and colloidal organic matter. It may include impurities or deposits that accumulate on the main parts of the engine's combustion chamber such as the cylinder head, piston, inlet valve, exhaust valve and injector tip (Fig. 1)[1], [2].

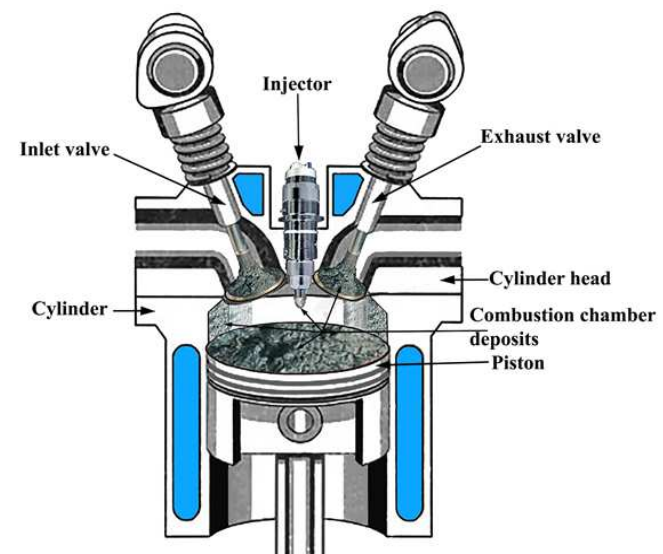

Fig.1. Deposits on different positions of the combustion chamber [3]
Deposits on various parts of the engine will adversely affect many engine parameters such as reducing air residue, limiting airflow, increasing the compression ratio, changing spray characteristics, knock, reducing thermal conductivity, and catalyst activity. Therefore, they have significant impacts on engine performance, fuel consumption, cold start, detonation and emissions through various issues raised by Salomatov [4]. Also, the combustion chamber deposits are stick to the exhaust valves and causing valve jam [5]. The deposits on the wall surface of the combustion chamber make it for engines hard to start, causing knock, increasing hydrocarbon emissions and running jerky without loads [6].

In real engines, there is always a large number of fuel droplets involved in the fuel injection process. The droplets evaporate and are burned in the combustion chamber space. However, some of the droplets collide with the wall surface in the combustion chamber settle. The interaction between the fuel and the surface of the combustion chamber wall can lead to the formation of a liquid fuel film on the wall. The formation of this liquid film is necessary for creating deposits on the wall surface of the combustion chamber [7].

In diesel engines, fuel injection collides with the combustion chamber wall is inevitable. The cause of the 
increased collision of fuel injection with wall surface in the high-temperature engine combustion chamber is:

- Higher injection pressure increases the penetration ability of the spray [8].

- The delay time is longer than the fuel injection time [9].

- The distance between the nozzle and the piston head is as short as that of a small high-speed engine [10].

- Fuel droplets should not be completely burned (for example, for biodiesel fuel) [11].

The interaction between the fuel spray and the wall surface of the combustion chamber leads to the formation of a thin fuel film layer on the wall surface. The amount of adhesion fuel and the interaction with the combustion chamber depends on the temperature on the wall surface. Also, the wall temperature determines the number of polymers and unstable components in the adhesion fuel. The liquid film will be thinner if the surface has a high temperature and the interaction occurs during the boiling phase. During this period, the fuel droplets move in chaos, so they bump into different areas of the wall surface in the combustion chamber or will be pushed out during the exhaust process. The liquid film adhered to the wall surface will undergo physical processes (heat transfer, evaporation, compaction) and chemistry (pyrolysis, polymerization) under high-temperature conditions [12].
The results of Stephan's study [13] show that the fuel spray interacts with the wall surface in different states including dry walls (all sprays evaporate above the interaction region); wet wall (thin liquid film on the surface) and Leidenfrost mechanism (forming a thin film on the surface). Therefore, the interaction between the fuel particles and the wall surface and the evaporation properties of the fuel play an important role in creating the fuel liquid film - a precondition of deposits formation on the wall surface [14]. It is also the basis for establishing tests on the evaporation characteristics of fuels before each deposits formation test.

During the combustion process, deposits formation, especially the formation of carbon deposits, is most serious because of the high-temperature gases and flame that increase carbonization. Moreover, soot particles also accumulate in this process. The high-temperature gases and flame also produce a part of the deposit, and this deposit is easily oxidized, resulting in a reduction in deposits on the combustion chamber wall. At the same time, the deposits can also be eroded by other ways such as the movement of the intake air and pistons and the vibrations. Then part of the deposits is removed by physical impact and the exhaust process [15]. The next fuel injection will affect the previously formed deposits. That process repeats until the engine stops working [16].
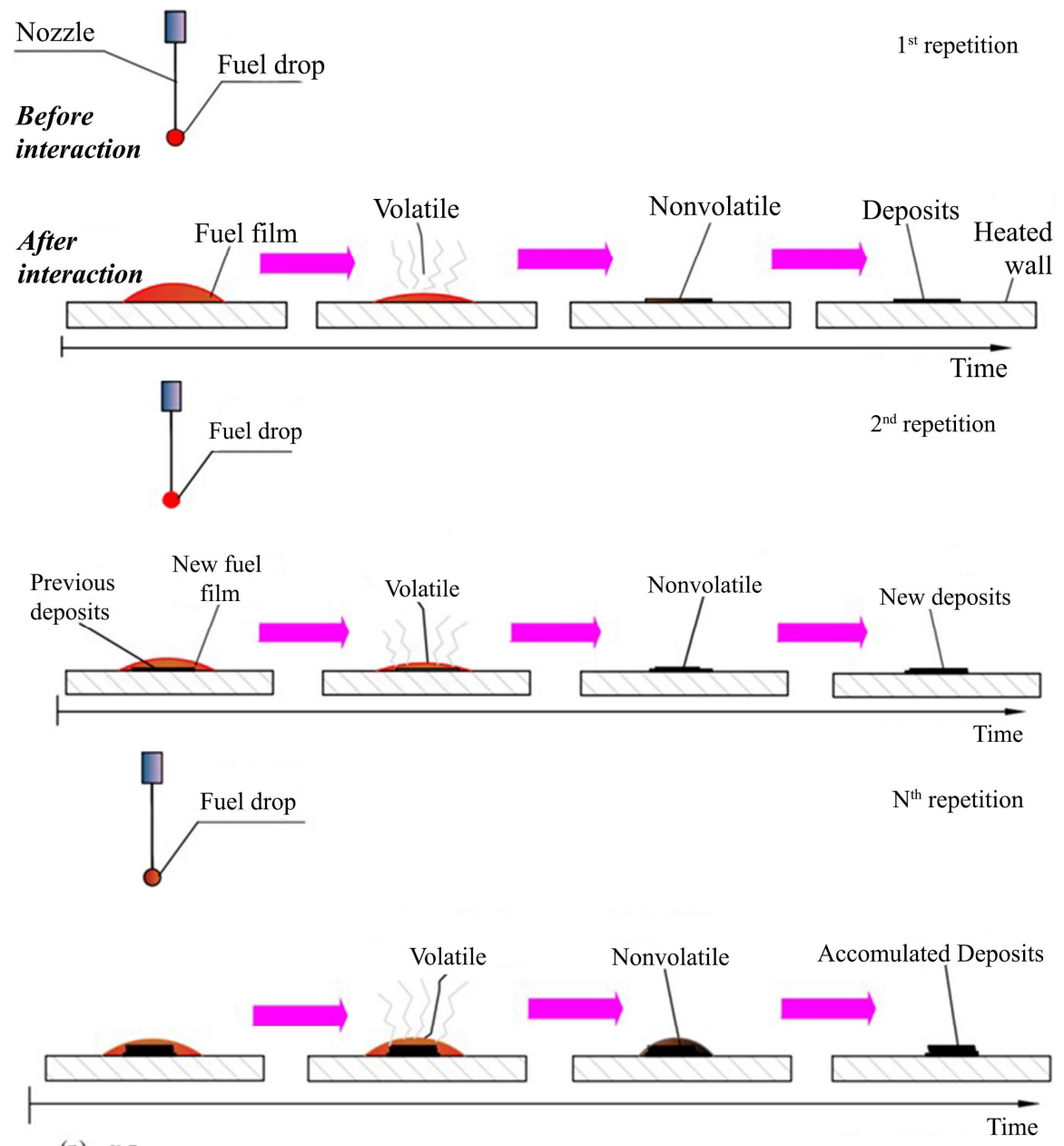

(n) $x \tau_{\text {imp }}$

Fig.2. Deposits accumulation process on the wall surface [17] 
During operation, continuous deposits are accumulated and cover the surface of the combustion chamber wall. However, in the real engines, after a certain time, the number of deposits accumulated on the surface will stop at the rate that the formed deposits and removed deposits are a balance [18].

Accumulating deposits in the engine is a complicated phenomenon, and it is difficult to observe its development and formation mechanism in a real engine [19]. Therefore, a simplified method by testing the deposits formed on the combustion chamber model is proposed in this study. This method is the repeating process of fuel droplets that continuously interact with the surface of the combustion chamber wall, leading to the accumulation of deposits on the wall surface [20], [21].

Repetition and deposits accumulated processes in this method are similar to the deposits formation due to the interaction of the fuel spray with the combustion chamber wall surface as described in Fig. 2. Therefore, the heated surface deposits formation test (HSDFT) was used in this study to simplify experimental research and still describe physical phenomena. The purpose of HSDFT is to simulate fuel deposition on the wall in the combustion chamber and to study the deposits development and formation mechanisms and factors that effect on the deposits formation process.

\section{MATERIAL AND METHOD}

\section{A. Factors affecting deposits formation}

1) Liquid film formation: The liquid film on the wall surface of the combustion chamber is one of the main causes of deposits formation. It acts as an intermediate layer created by contact, condensation of fuel and lubricating oil on various details in the engine combustion chamber[22]. The film appears first due to the interaction between the fuel molecules with high concentration and the wall surface of the combustion chamber during the spraying process. In engines that have this kind of a fuel liquid film formation, the thickness of the deposit builds up on the surface of the combustion chamber wall depending on the surface temperature and the interactive position [23]. The formation of a fuel liquid film, the number of accumulated deposits in the working process of the engine is different in value and position in the combustion chamber due to different mechanisms and various temperature of the wall surface.

2) Wall surface temperature: Wall temperature effect is the most important factor leading to deposits formation, in which flame temperature and cylinder surface temperature are important factors. High temperatures of flames and combustion chambers cause intense carbonization[24]. Different parts of the combustion chamber have different temperatures and contact with the deposits formation components differently. The highest heat flow occurs in the area between the cylinder head, near the exhaust valve and at the center of the piston top. Large amounts of deposits often accumulate on the top of the piston, where there is high stress and close to the nozzle [25]. The largest deposit thickness is usually found at the top edge of the piston with the lower temperature. At other locations such as inlet valve and exhaust valve, due to higher surface temperature, the number of deposits will be less.

3) Fuel and lubricating oil: The formation of deposits in the combustion chamber is also greatly influenced by factors such as fuel, lubricating oil or a combination of both. However, the fuel and lubricating oil content in the deposits depends on the type of engine and the arrangement of parts in the combustion chamber [26-28]. Deposits in high temperatures areas of combustion chambers are mainly mineral ores from the process of evaporation or combustion of fuels and lubricants.

\section{B. The basis for designing experimental model}

When direct injection of fuel into the cylinder, the two main physical processes that can occur including the interaction between the spray and the wall surface, and the thin films formation. Both of these processes can affect the combustion efficiency and formation of pollutants [7]. Whether the spray-wall interaction occurs or not depends on the length of the spray and the distance between the nozzle and the combustion chamber wall. Depending on the temperature of the combustion chamber wall and the amount of liquid deposited on the wall of spray-wall interaction, there may be both negative and positive effects (Fig. 3).

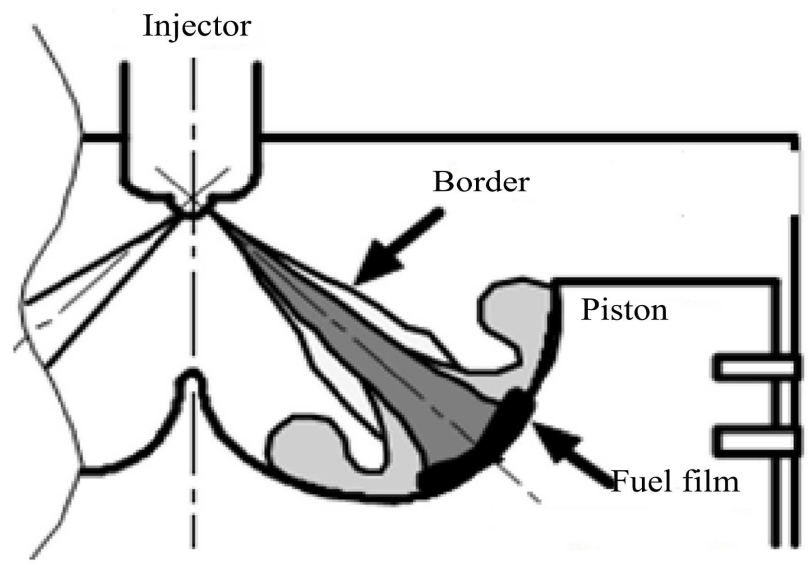

Fig.3. Interaction of the fuel spray with the combustion chamber wall [29]

Mechanism of decay of fuel spray: secondary decay plays a decisive role in the formation of fuel liquid film on the wall surface because it governs the ability to separate fuel particles from the spray [22]. The secondary decay process occurs when the surface tension of the fuel droplet is small, affecting the resistance to the deformation of the fuel droplet. The secondary decay of fuel droplets occurs mainly due to the impact of aerodynamics, so the relative speed of fuel droplets with ambient air plays an important role in the secondary decay mechanism. This decomposition process is expressed through the Weber number.

Arcoumanis et al. [30] developed the research of Wierzba [31] and showed that the mechanism of droplet decay depends on different We value, We are in the range 1001000 , the decay takes place according to rules law, and chaotic decay when $\mathrm{We} \geq 1000$.

Table 1 shows that, at We numbers very low $(\mathrm{We} \approx 12$ ), drops only deform without decay. When We increased (12 $\leq$ We <45), in the spray, appeared an additional decay mechanism in the form of saccular or film. In this decay 
mechanism, fuel droplets vibrate with large amplitudes, which decay into smaller droplets and occur in two modes of droplet size distribution; If $\mathrm{We} \geq 45$, the mechanism of decaying into small droplets occurs faster even when $\mathrm{We} \geq$ 1000 , decay occurs at the nozzle [18].

TABLE I

THE INFLUENCE OF WE ON THE DECAY MECHANISM [30]

\begin{tabular}{|c|c|c|}
\hline Fuel spray breaking mechanism & We & Sơ đồ Arcoumanis et, al \\
\hline Vibration decay & $\approx 12$ & $\circ 8 \stackrel{\circ}{\circ}$ \\
\hline Saccular decay & $12 \leq \mathrm{We}<18$ & 0 \\
\hline Saccular/film decay & $18 \leq \mathrm{We}<45$ & ○ीक की: की \\
\hline Delamination / chaos decay & $45 \leq \mathrm{We}<350$ & $0 \sqrt{\sum_{y}^{*}} \mathbb{E}_{i y}^{\prime \prime} \mathbb{C}$ \\
\hline Wave decay & $350 \leq \mathrm{We}<1000$ & 0 相 \\
\hline Intense decay & $1000 \leq \mathrm{We}$ & O \\
\hline
\end{tabular}

According to Westerling [32] and Farrel's study [33] to maintain the liquid film on the surface when the fuel droplets interacting with the heated wall surface, the We number must be maintained: $80<\mathrm{We}<150$. Meanwhile, according to the study of Tuan Tran, We have a close relationship between surface and number of surface temperatures (Fig. 4) [20], [32]:

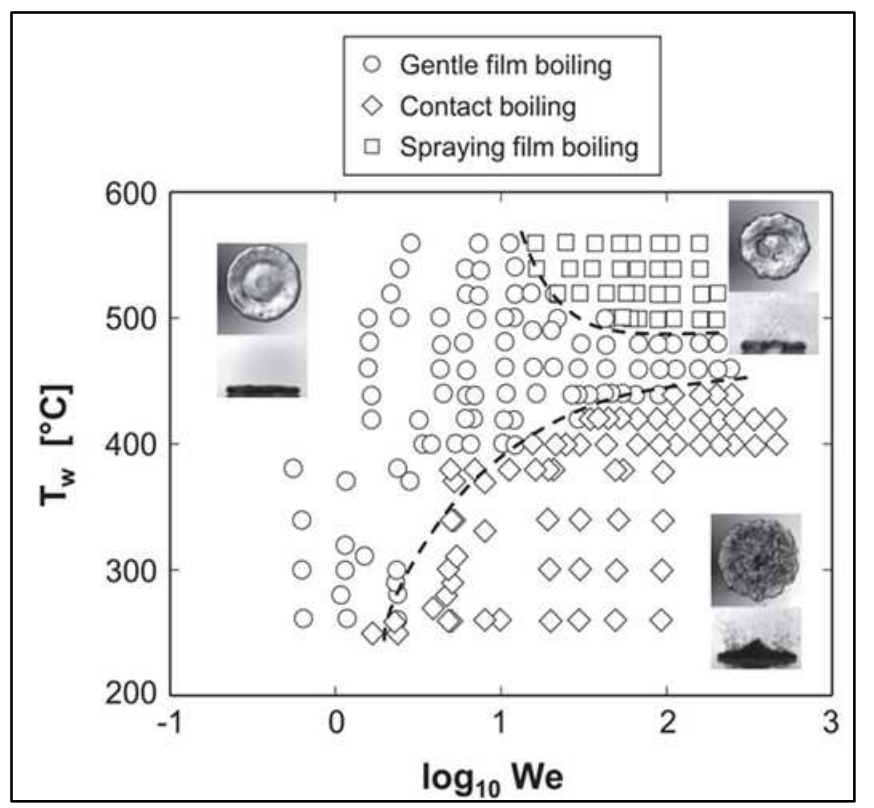

Fig.4. The effect of We number and heated wall temperature to the interaction state of droplets [34]

Thus, when evaluating the correlation of numbers, We with the droplet morphology when interacting with the wall in both the combustion engine chamber and the droplet model on the heated wall surface shows that with $\mathrm{We}=110$ is suitable to select input parameters.

\section{RESULTS AND DISCUSSION}

\section{A. Design and Manufacture Equipment for HSDFT experimental model}

The results of calculating the basic parameters of the experimental model determine the combustion chamber deposits formed on the heated metal surface is shown in Table 3.

TABLE II

RESULTS OF DIESEL FUEL ANALYSIS (DO)

\begin{tabular}{|c|c|c|c|c|}
\hline Indicators & Units & Result & Range & Test method \\
\hline Density at $15^{\circ} \mathrm{C}$ & $\mathrm{Kg} / \mathrm{m}^{3}$ & 823 & $820-860$ & ASTM D1298 \\
\hline $\begin{array}{l}\text { Surface tension } \\
\text { at } 40^{\circ} \mathrm{C}\end{array}$ & $\mathrm{mN} / \mathrm{m}$ & 25,4 & & ASTM D971 \\
\hline Sulphur content & $\mathrm{mg} / \mathrm{kg}$ & 380 & $500, \max$ & ASTM D 2622 \\
\hline Cetane number & & 49 & $50, \max$ & ASTM D 613 \\
\hline $\begin{array}{l}\text { Distilled } \\
\text { temperature at } \\
90 \% \text { of } \\
\text { recovered } \\
\text { volume }\end{array}$ & ${ }^{\circ} \mathrm{C}$ & 332 & $355, \max$ & ASTM D 86 \\
\hline Flash point & ${ }^{\circ} \mathrm{C}$ & 60 & $55, \min$ & ASTM D 93 \\
\hline $\begin{array}{l}\text { Kinematic } \\
\text { viscosity at } \\
40^{\circ} \mathrm{C}\end{array}$ & $\mathrm{mm}^{2} / \mathrm{s}$ & 3,13 & $2,0-4,5$ & ASTM D 445 \\
\hline Pure point & ${ }^{\circ} \mathrm{C}$ & +3 & $+6, \max$ & ASTM D 97 \\
\hline Water content & $\mathrm{mg} / \mathrm{kg}$ & 50 & $200, \max$ & ASTM D 6304 \\
\hline $\begin{array}{l}\text { Poly aroma } \\
\text { hydrocarbon } \\
\text { content (PAH) }\end{array}$ & $\%$ mass & 9 & $11, \max$ & ASTM D 5186 \\
\hline
\end{tabular}

TABLE III

CALCUlation We, V AND LH

\begin{tabular}{|c|c|c|c|c|}
\hline Content & Symbol & Unit & Formula & Result \\
\hline Density of fuel & $\rho_{\mathrm{nl}}$ & $\mathrm{kg} / \mathrm{m}^{3}$ & DO & 823 \\
\hline $\begin{array}{l}\text { The surface } \\
\text { tension of fuel }\end{array}$ & $\sigma$ & $\mathrm{mN} / \mathrm{m}$ & DO & 25.4 \\
\hline $\begin{array}{l}\text { Gravity } \\
\text { acceleration }\end{array}$ & $\mathrm{g}$ & $\mathrm{m} / \mathrm{s}^{2}$ & - & 9.81 \\
\hline $\begin{array}{l}\text { The average } \\
\text { diameter of fuel } \\
\text { droplets }\end{array}$ & $\mathrm{D}_{\mathrm{d}}$ & $\mathrm{m}$ & - & 0.0023 \\
\hline Weber number & We & & $W e=\frac{\rho v^{2} D_{d}}{\sigma}$ & $\begin{array}{r}80 \\
110 \\
150\end{array}$ \\
\hline $\begin{array}{l}\text { The velocity of } \\
\text { droplets when } \\
\text { interacting with } \\
\text { the wall surface }\end{array}$ & $\mathrm{v}$ & $\mathrm{m} / \mathrm{s}$ & $v=\sqrt{\frac{W e \sigma}{\rho D_{d}}}$ & $\begin{array}{l}1.03 \\
1.21 \\
1.42\end{array}$ \\
\hline $\begin{array}{l}\text { Distance from } \\
\text { small needle to } \\
\text { the wall surface }\end{array}$ & $\mathrm{L}_{\mathrm{h}}$ & $\mathrm{m}$ & $L_{h}=\frac{v^{2}}{2 g}$ & $\begin{array}{l}0.055 \\
0.075 \\
0.102\end{array}$ \\
\hline
\end{tabular}

Equipment in deposits formation testing model on a heated surface is arranged as shown in Fig. 5, Fig. 6 and Fig. 7. This model is used to conduct three tests: droplet test, 
evaporation test and deposits formation test on the model of the combustion chamber wall surface.

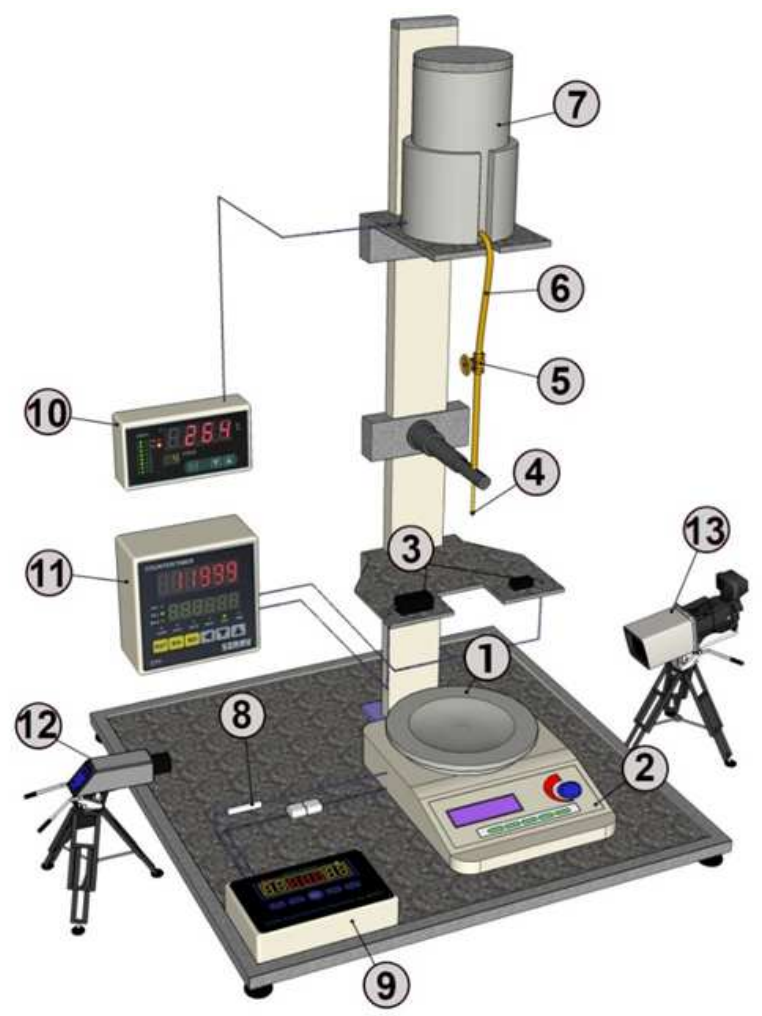

1.Aluminum alloy plate; 2 . Heating unit; 3 . Sensors detect drops; 4 . Needle created drops; 5 . Throttle valve; 6 . Fuel pipe; 7. Fuel tank; 8 . Temperature sensor; 9. Temperature controller; 10. Fuel Heater; 11. Dropping signal receiver; 12. Infrared thermometer; 13. Camera

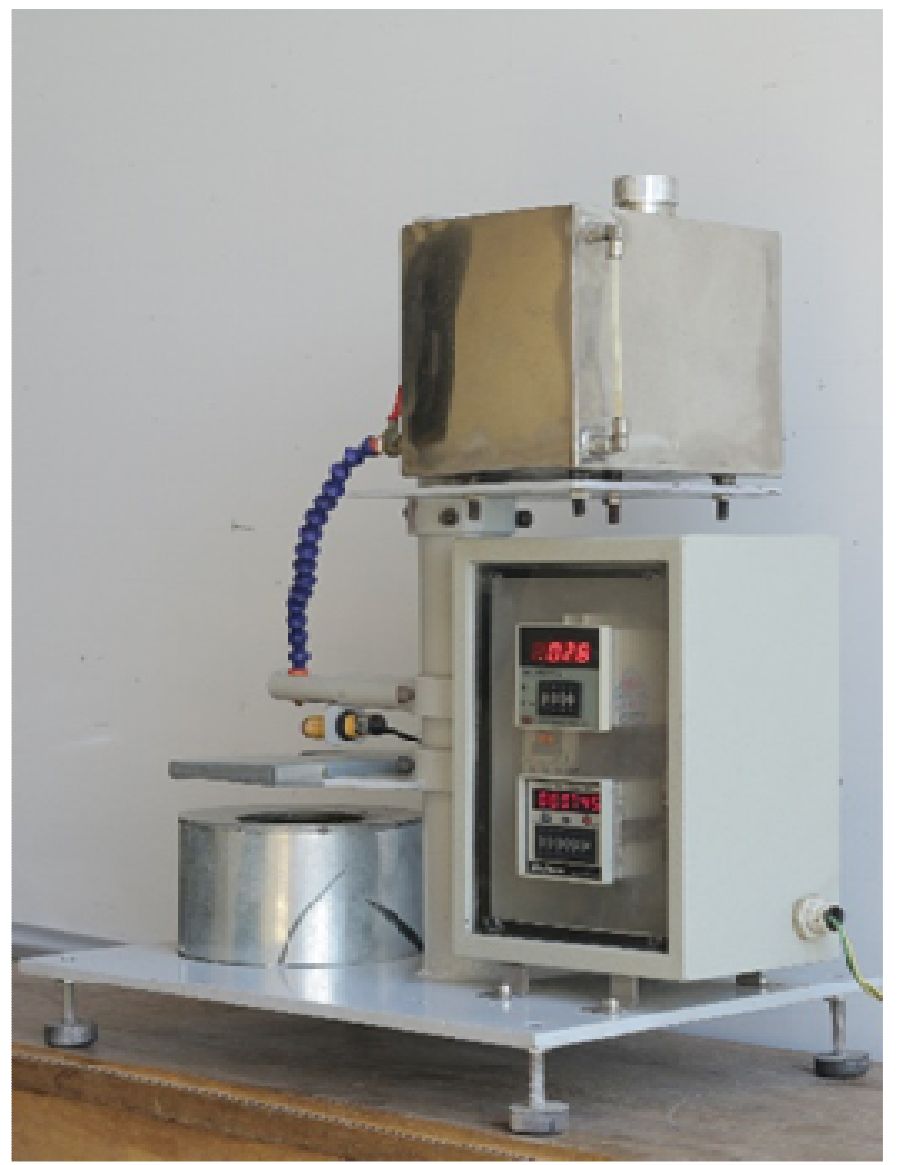

Fig.6 HSDFT model

Fig. 5 The layout diagram of HSDFT model

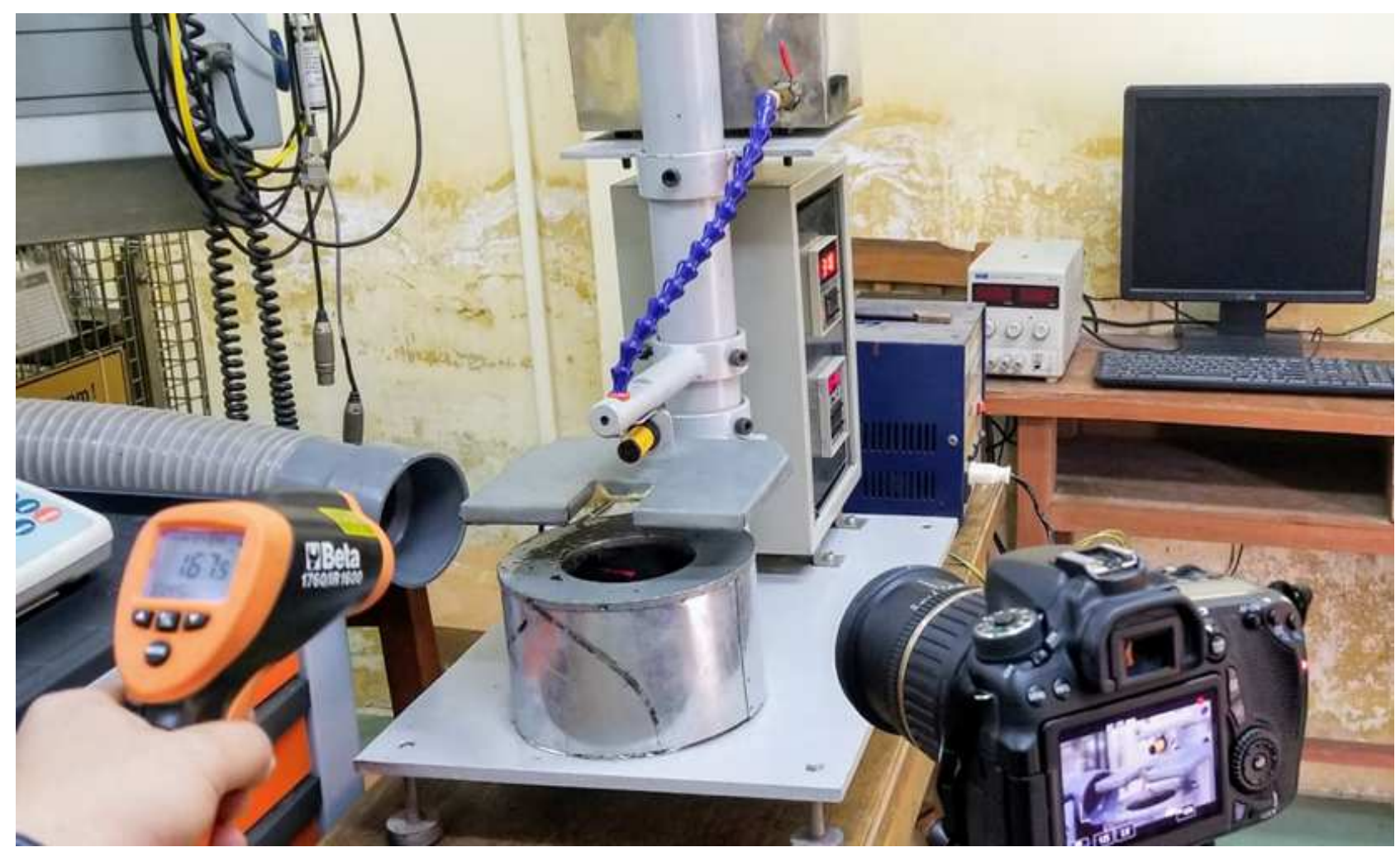

Fig. 7 The arrangement of HSDFT model in 3 tests 
To ensure heat transfer capability, the material of the base plate of the model is selected as an aluminum alloy (AC9A). The temperature of the base plate is maintained and controlled via a resistor-type heating device with a maximum power of about $500 \mathrm{~W}$. The temperature controller operates through the voltage signal transmitted from the thermocouple pair with the temperature sensor WRET-01 (K-type) placed below the ground plate. Temperature controller with 7-segment LED relay display, setting temperature above and below switch off, 220VAC working voltage. However, due to the loss of heat from the heated wall surface to the surrounding environment, the temperature measured from the thermocouple has a relative error (about $5^{\circ} \mathrm{C}$ to $8^{\circ} \mathrm{C}$ ). Therefore, the Beta $1760 /$ IR 1600 infrared thermometer is added to measure the outer surface temperature of the base plate. The distance from the droplet to the substrate surface is based on the condition of maintaining the liquid fuel film on the hot surface after the fuel droplets interact. The calculation process selected $\mathrm{L}_{\mathrm{h}}=$ $80 \mathrm{~mm}$ to maintain the Weber number $=110$ and limit the error due to the lack of fuel droplets during the experiment. The amount of interactive droplets $\left(\mathrm{N}_{\mathrm{D}}\right)$ is adjusted through the throttle valve, thus adjusting the fuel droplet interactive time interval to maintain the condition of fuel liquid film formation. A set of devices including infrared laser detectors and drop detection signal receivers is equipped to determine the number of fuel droplets that have escaped to the needle.

\section{B. HSDFT testing process}

1) Evaporation test: Evaporation test aims to determine the evaporation characteristics of the fuels involved in the test. The fuel used in the evaporation tests is dodecane (DDC: $\mathrm{C} 12 \mathrm{H} 26$ ) and all fuels involved in testing (diesel and biodiesel). The HSDFT model is used to perform the evaporation test with the set parameters including the number of interactive droplets of 100 drops for each fuel type. The heating capacity of the heater for the base plate and the evaporation properties of each fuel will determine the temperature range of the evaporation test. Previous studies suggest that the maximum thermal range of the test model is from $125^{\circ} \mathrm{C}$ to $410^{\circ} \mathrm{C}$. With the permissible temperature error of $5^{\circ} \mathrm{C}$. Each fuel has a different density, so the mass of fuel droplets is different.

The correlation between density and fuel droplet diameter is also taken into account by taking the average diameter of the fuel droplet. The average diameter of the fuel droplet is determined by a high-speed camera with an accuracy of $0.1 \%$ and compared with the diameter of the needle to create the droplet. At least three tests are performed for each heat level to ensure the reliability of the experimental data. The high-speed camcorder Sony A9 records the evaporation process of fuel droplets when interacting with the wall surface. That data helps to analyze and determine the start and end times of evaporation of a drop of fuel. The continuous evaporation of single fuel droplets was conducted before each test to create deposits on the HSDFT model. This test helps to determine the fuel droplet lifetime during the evaporation process and supports basic studies of the mechanism of deposits formation of fuel in the engine's combustion chamber.
2) Deposits formation test by HSDFT model: The deposits formation of various fuels is carried out on the HSDFT model with the following input parameters: the number of interactive fuel droplets for each measurement of the formation is 1000 drops. The ABS 220-4N electronic microbalance will determine the number of deposits collected, and an image of deposits is recorded with the camera. The presence of deposits on the wall surface and heat storage on the wall surface may affect the accuracy of the data at subsequent tests. Therefore, it is necessary to clean the wall surface and cool the plate surface after each measurement. The total number of fuel droplets in each experiment was determined based on the rules of experimental planning and thermal limit of HSDFT model. Accordingly, the proposed total number of interactive fuel droplets is 19,000 drops for each fuel participating in the experiment.

Besides, the microstructure structure and the composition of the deposits sample were analyzed by Jeol SEM 5410 LV scanning electron microscope. Therefore, the residue sample collected after every 1000 drops will be stored in a desiccator to ensure the reliability of the sample.

The correlation between the $T_{i}$ indicator temperature that is obtained from the temperature sensor placed in the base plate and the $T_{S}$ substrate surface temperature that is obtained from the infrared thermometer (Beta 1760 / IR1600) with the emission of 0.90 considered when determining the surface temperature of hot walls (Fig. 8).

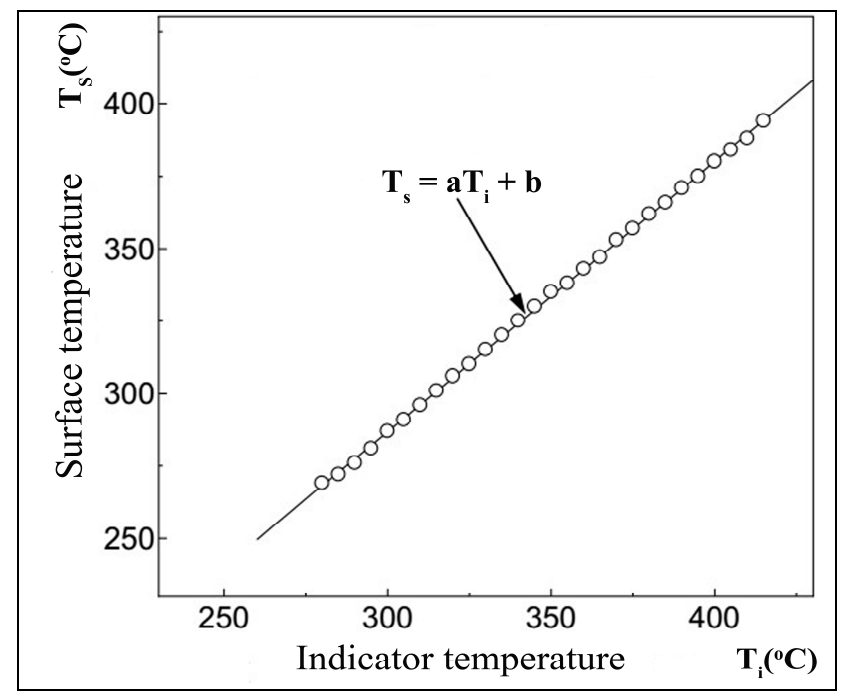

Fig. 8. The curriculum design process

Data for maximum and minimum surface temperatures of deposits $\left(\mathrm{T}_{\mathrm{d}}\left[{ }^{\circ} \mathrm{C}\right]\right)$ during the interaction period were collected using an infrared thermometer (Beta 1760 / IR1600) with emission level by 0.90 to control the impact of heat change during the deposition process. Meanwhile, the metal wall surface temperature related to the indicator temperature (Ti $\left[{ }^{\circ} \mathrm{C}\right]$ ) is obtained by thermocouple and surface temperature $\left(\mathrm{T}_{\mathrm{S}}\left[{ }^{\circ} \mathrm{C}\right]\right)$ measured through an infrared thermometer. The correlation between $\mathrm{T}_{\mathrm{i}}$ and $\mathrm{T}_{\mathrm{S}}$ is the basis for determining the temperature of the wall surface (Fig. 8). 


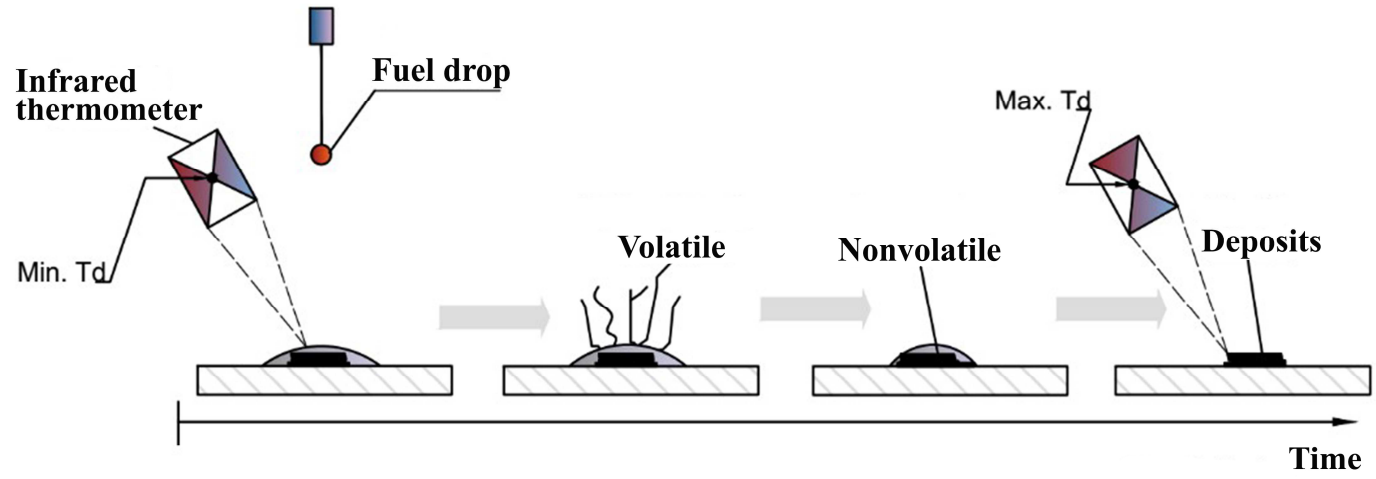

Fig. 9. The process of measuring deposits surface temperature

Figure 9 shows the surface temperature measurements using an infrared thermometer. The minimum deposit surface temperature is measured now when the fuel droplets are interacting with the deposits surface. The maximum deposits surface temperature is measured at the point just before the next droplets interacting with the deposits surface. The maximum deposits surface temperature and fuel evaporation properties are used to estimate fuel droplet lifetime in deposition test.

\section{CONCLUSIONS}

The HSDFT experimental model is an initial basic step in the process of studying a simple method to investigate the formation and development of deposits in combustion chambers of diesel engines using different fuels. The experimental model overcomes difficulties and the complexity of the experimental studies about deposits formation in real engines. This model has shown its potential when it is possible to investigate the formation of deposits when using biodiesel that tends to form significant deposits when used as fuel. This replaces traditional diesel fuel in real engines. Moreover, it helps researchers avoid the risk of damaging the real engine when using new biodiesel fuels in studies of combustion chambers. The HSDFT model shows quite a lot of phenomena and physical properties of fuel when interacting with hot metal wall surfaces. However, although there is a good similarity to the physical model with the combustion chamber in the engine, the effects of pressure and dynamics of fuel gas are not yet considered in this study.

\section{REFERENCES}

[1] X. Zhang et al., "Investigating the microstructures of piston carbon deposits in a large-scale marine diesel engine using synchrotron Xray microtomography," Fuel, vol. 142, pp. 173-179, 2015.

[2] A. T. Hoang and V. V. Pham, "Impact of jatropha oil on engine performance, emission characteristics, deposit formation, and lubricating oil degradation," Combust. Sci. Technol., vol. 191, no. 03, pp. 504-519, 2019.

[3] A. T. Hoang and V. V. Pham, "A study of emission characteristic, deposits, and lubrication oil degradation of a diesel engine running on preheated vegetable oil and diesel oil," Energy Sources, Part A Recover. Util. Environ. Eff., vol. 41, no. 5, pp. 611-625, 2019.

[4] V. V Salomatov, G. V Kuznetsov, and S. V Syrodoy, "The comparative analysis of heat transfer efficiency in the conditions of formation of ash deposits in the boiler furnaces, with taking into account the crystallization of slag during combustion of coal and water-coal fuel," in Journal of Physics: Conference Series, 2017, vol.
891 , no. 1 , p. 12240.

[5] A. T. Hoang and A. T. Le, "A review on deposit formation in the injector of diesel engines running on biodiesel," Energy Sources, Part A Recover. Util. Environ. Eff., pp. 1-16, 2018.

[6] V. V. Pham, "Analyzing the effect of heated wall surface temperatures on combustion chamber deposit formation," J. Mech. Eng. Res. Dev., vol. 41, no. 4, pp. 17-21, 2018.

[7] A. T. Hoang and V. D. Tran, "Experimental Analysis on the Ultrasound-based Mixing Technique Applied to Ultra-low Sulphur Diesel and Bio-oils," Int. J. Adv. Sci. Eng. Inf. Technol., vol. 9, no. 1, pp. 307-313, 2019.

[8] A. T. Hoang and M. T. Pham, "Influences of heating temperatures on physical properties, spray characteristics of bio-oils and fuel supply system of a conventional diesel engine," Int. J. Adv. Sci. Eng. Inf. Technol., vol. 8, no. 5, pp. 2231-2240, 2018.

[9] R. Pos, R. Cracknell, and L. Ganippa, "Transient characteristics of diesel sprays from a deposit rich injector," Fuel, vol. 153, pp. 183191, 2015.

[10] V. V. Pham and D. T. Cao, "A brief review of technology solutions on fuel injection system of diesel engine to increase the power and reduce environmental pollution," J. Mech. Eng. Res. Dev., vol. 42, no. 01, pp. 01-09, 2019.

[11] T. Long, M. Li, Y. Chen, and X. Zhu, "Study on Evaporation Characteristics of Bio-oil and its Compound Models," BioResources, vol. 9, no. 3, pp. 4242-4252, 2014.

[12] C. Rodrigues, J. Barata, and A. Silva, "Influence of the energy dissipation in the spray impingement modeling," in 50th AIAA Aerospace Sciences Meeting including the New Horizons Forum and Aerospace Exposition, 2012, p. 349.

[13] P. Hänichen, M. van Eyk, and P. Stephan, "Experimental investigations of fuel film evaporation with deposit formation," Int. J. Heat Fluid Flow, vol. 70, pp. 125-130, 2018.

[14] A. T. Hoang, A. T. Le, and V. V. Pham, "A core correlation of spray characteristics, deposit formation, and combustion of a high-speed diesel engine fueled with Jatropha oil and diesel fuel," Fuel, vol. 244, pp. 159-175, 2019.

[15] P. Forooghi et al., "DNS of momentum and heat transfer over rough surfaces based on realistic combustion chamber deposit geometries," Int. J. Heat Fluid Flow, vol. 69, pp. 83-94, 2018.

[16] B. Sugiarto, M. T. Suryantoro, S. Yubaidah, and M. I. Attharik, "The effect of antioxidant additives on the growth of deposits on the use of biodiesel fuel (B100) at certain temperatures," in IOP Conference Series: Earth and Environmental Science, 2018, vol. 105, no. 1, p. 12075.

[17] A. T. Hoang, V. V. Le, V. V. Pham, and B. C. Tham, "An investigation of deposit formation in the injector, spray characteristics, and performance of a diesel engine fueled with preheated vegetable oil and diesel fuel," Energy Sources, Part A Recover. Util. Environ. Eff., pp. 1-13, 2019.

[18] P. Singer and J. Rühe, "On the mechanism of deposit formation during thermal oxidation of mineral diesel and diesel/biodiesel blends under accelerated conditions," Fuel, vol. 133, pp. 245-252, 2014.

[19] Y. Kidoguchi, Y. Nada, S. Sangawa, M. Kitazaki, and D. Matsunaga, "Effect of low load combustion and emissions on fuel dilution in lubricating oil and deposit formation of DI diesel engines fueled by straight rapeseed oil," Fuel, vol. 221, pp. 35-43, 2018.

[20] M. A. Hoffman, B. J. Lawler, Z. S. Filipi, O. A. Güralp, and P. M. 
Najt, "Development of a device for the nondestructive thermal diffusivity determination of combustion chamber deposits and thin coatings," J. Heat Transfer, vol. 136, no. 7, p. 71601, 2014.

[21] A. T. Hoang, "Waste heat recovery from diesel engines based on Organic Rankine Cycle,” Appl. Energy, vol. 231, pp. 138-166, 2018.

[22] H. Zhou, B. Zhou, H. Zhang, and L. Li, "Behavior of fouling deposits formed on a probe with different surface temperatures," Energy \& Fuels, vol. 28, no. 12, pp. 7701-7711, 2014.

[23] M. T. Suryantoro, B. Sugiarto, and F. Mulyadi, "Growth and characterization of deposits in the combustion chamber of a diesel engine fueled with B50 and Indonesian biodiesel fuel (IBF)," Biofuel Res. J., vol. 3, no. 4, pp. 521-527, 2016.

[24] S. S. Sazhin et al., "A simplified model for bi-component droplet heating and evaporation," Int. J. Heat Mass Transf., vol. 53, no. 2122, pp. 4495-4505, 2010.

[25] M. Husnawan, H. H. Masjuki, T. M. I. Mahlia, and M. G. Saifullah, "Thermal analysis of cylinder head carbon deposits from single cylinder diesel engine fueled by palm oil-diesel fuel emulsions," Appl. Energy, vol. 86, no. 10, pp. 2107-2113, 2009.

[26] L. R. Rudnick, Lubricant additives: chemistry and applications. CRC press, 2017.

[27] A. T. Hoang, "Experimental study on spray and emission characteristics of a diesel engine fueled with preheated bio-oils and diesel fuel," Energy, vol. 171, pp. 795-808, 2019.
[28] A. T. Hoang and A. T. Le, "Trilateral correlation of spray characteristics, combustion parameters, and deposit formation in the injector hole of a diesel engine running on preheated Jatropha oil and fossil diesel fuel," Biofuel Res. J., vol. 6, no. 1, pp. 909-919, 2019.

[29] A. T. Hoang, "Prediction of the density and viscosity of biodiesel and the influence of biodiesel properties on a diesel engine fuel supply system," J. Mar. Eng. Technol., pp. 1-13, 2018. https://doi.org/10.1080/20464177.2018.1532734.

[30] C. Arcoumanis, H. Flora, M. Gavaises, and M. Badami, "Cavitation in real-size multi-hole diesel injector nozzles," SAE Trans., pp. $1485-1500,2000$

[31] A. Wierzba, "Deformation and breakup of liquid drops in a gas stream at nearly critical Weber numbers," Exp. Fluids, vol. 9, no. 1-2, pp. 59-64, 1990.

[32] L. H. J. Wachters and N. A. J. Westerling, "The heat transfer from a hot wall to impinging water drops in the spheroidal state," Chem. Eng. Sci., vol. 21, no. 11, pp. 1047-1056, 1966.

[33] A. E. Farrell, R. J. Plevin, B. T. Turner, A. D. Jones, M. O'Hare, and D. M. Kammen, "Ethanol can contribute to energy and environmental goals," Science (80-. )., 2006.

[34] T. Tran, H. J. J. Staat, A. Prosperetti, C. Sun, and D. Lohse, "Drop impact on superheated surfaces," Phys. Rev. Lett., vol. 108, no. 3, p. 36101, 2012. 